\title{
TITLE:
}

\section{$<$ Note $>$ Discriminating Saba and Landolphia Seeds in Chimpanzee Feces at Mahale}

AUTHOR(S):

Nakamura, Michio

CITATION:

Nakamura, Michio. < Note> Discriminating Saba and Landolphia Seeds in Chimpanzee Feces at Mahale. Pan Africa News 2014, 21(1): 3-6

ISSUE DATE:

2014-06

URL:

http://hdl.handle.net/2433/188629

RIGHT:

Copyright (C) Pan Africa News. 
Table 1. Details of encounters with crocodiles, Mt. Assirik, Senegal.

\begin{tabular}{lcccl}
\hline Date & Habitat type & Place & Length (m) & Comments \\
\hline 28-Apr-76 & ?? & Hidden Valley & $1.2-1.5$ & Dead in pool; in steep-sided bat grotto; maggots \\
10-Jun-76 & ?? & Stella's Valley & ?? & In stream \\
14-Feb-77 & W & Lower Lion Valley & 1.5 & Flees from bank into pool \\
07-Mar-77 & G & Tsetse Plains & small & Only intermittent pools but some running water \\
04-Jan-78 & F & Elephant Rib Valley & 1.5 & Slides into pool \\
02-Nov-78 & F & Elephant Rib Valley & $0.9-1.2$ & Beginning of forest \\
13-Feb-79 & F & Middle Lion Valley & 1.2 & Stream; upstream from bathing pool \\
14-Mar-79 & G & Tsetse Plains & 0.6 & Pool \\
\hline 25-Apr-79 & F & Middle Lion Valley & ?? & Old Camp bathing pool \\
\hline
\end{tabular}

Habitat type: $\mathrm{F}$ = forest, $\mathrm{G}$ = grassland, $\mathrm{W}=$ woodland

habitat types. All crocodiles were immature, ranging from 1-1.5 m long. All retreated upon encountering us, into whatever water was available.

Lacking permanent surface water, Assirik is probably too dry to maintain a population of crocodiles, but it seems likely that young crocodiles disperse in the rainy season up the rain-swollen tributaries of the Gambia River, bringing some of them into the main valleys of the study area. Those that did not retreat with the advancing dry season were probably trapped in diminishing pools, where they were temporarily more exposed and observable, but ultimately perished.

Are crocodiles a predatory threat to the Assirik chimpanzees? Perhaps.

\section{ACKNOWLEDGEMENTS}

I thank the 15 other researchers who took data on animal encounters during the Assirik project, especially Caroline Tutin and the late Pamela Baldwin; Kazuhiko Hosaka and Michio Nakamura for helpful comments and suggestions on the manuscript. Writing of this report was supported by an Emeritus Fellowship from The Leverhulme Trust.

\section{REFERENCES}

Angus S 1971. Water-contact behavior of chimpanzees. Folia Primatol 14:51-58.

Cheney DL, Seyfarth RM 2007. Baboon Metaphysics. University of Chicago Press, Chicago.

Galdikas BMF, Yeager CP 1984. Crocodile predation on a crabeating macaque in Borneo. Am J Primatol 6:49-51.

Galdikas BMF 1985. Crocodile predation on a proboscis monkey in Borneo. Primates 26:495-496.

IUCN 2013. IUCN Red List of Threatened Species. http://www. iucnredlist.org/details/46590/0

McGrew WC 1977. Socialization and object manipulation of wild chimpanzees. In: Primate Bio-social Development. Chevalier-Skolnikoff S, Poirier FE (eds), Garland, New York, pp. 261-288.

McGrew WC, Baldwin PJ, Tutin CEG 1981. Chimpanzees in a hot, dry and open habitat: Mt. Assirik, Senegal, West Africa. J Hum Evol 10:227-244.

McGrew WC, Marchant LF, Nishida T (eds.) 1996. Great Ape Societies. Cambridge University Press, Cambridge.

Nishida T 1980. Local differences in responses to water among wild chimpanzees. Folia Primatol 33:189-209.

Njau JK, Blumenschine RJ 2012. Crocodylian and mammalian carnivore feeding traces on hominid fossils from FLK22 and FLK NN 3, Plio-Pleistocene, Olduvai Gorge, Tanzania. J Hum Evol 63:408-417.

\section{$<$ NOTE >}

\section{Discriminating Saba and Landolphia Seeds in Chimpanzee Feces at Mahale}

\author{
Michio Nakamura \\ Wildlife Research Center, Kyoto University, Japan \\ (E-mail:nakamura@wrc.kyoto-u.ac.jp)
}

\section{INTRODUCTION}

The fruits of Saba comorensis (local name, ilombo) and Landolphia owariensis (local name, mpila) are often enthusiastically eaten by chimpanzees at Mahale, and they have been classified as a "major food" and "important food," respectively, by Nishida (1991). Both of them belong to the family Apocynaceae with liana life forms, and they share some common characteristics. However, the 


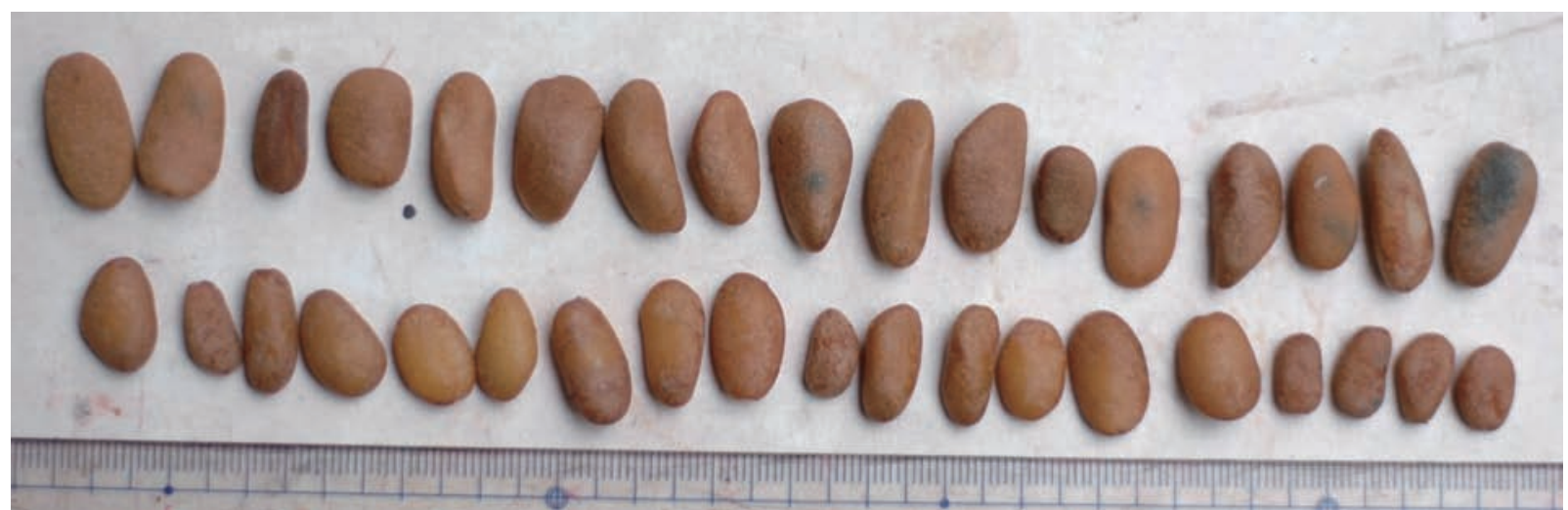

Figure 1. Seeds of Saba (above) and Landolphia (below). Although the former is slightly larger than the latter, it is not easy to distinguish between the seeds in chimpanzee feces.

fruits of Saba and Landolphia are easily distinguishable by their color and size: the ripe fruit-shell color of Saba is yellow, while that of Landolphia is orange; the color of the fruit pulp is yellow in the former and white in the latter, and the fruit size of the former (typically ca. $7-10 \mathrm{~cm}$ in fruit-shell diameter) is about twice as large as that of the latter (ca. $3.5-5 \mathrm{~cm}$ ). Therefore, no researchers would confuse these species when they actually observe chimpanzees eating these fruits.

However, it is very difficult to identify the seeds found in chimpanzee feces (see McGrew et al. 2009 for the standard protocol for fecal analysis). Chimpanzees typically swallow seeds of both species together with the fruit pulp. Seeds are then defecated intact in their feces. The shapes and colors of their seeds resemble each other and are thus not easily distinguishable (Figure 1). Because these fruits are available in the same season, it is also not possible to discriminate them by season. Therefore, Saba and Landolphia were clumped together in most previous studies on seed dispersal and fecal analyses at Mahale (Nishida \& Norikoshi n.d.1, n.d.2; Takasaki 1983; Takasaki \& Uehara 1984). However, because Saba is the most important fruit species for Mahale chimpanzees, it may be useful to develop some simple criteria to distinguish its seeds from those of Landolphia. The SabaLandolphia problem in fecal analyses may go beyond Mahale, because different species of these two genera are known to coexist in some other chimpanzee study sites (e.g., Saba senegalensis and Landolphia heudelotii are eaten by Assirik chimpanzees in Senegal: McGrew et al. 1988).

\section{METHODS}

I collected 25 Saba seeds and 28 Landolphia seeds from ripe fruits (five to six fruits each) of these plants in December 2013 at the Mahale Mountains National Park, Tanzania. The fruits were collected from the middle of the home range of the habituated $\mathrm{M}$ group. The sampling was performed opportunistically because of the difficulty in randomly collecting fruits from the high canopy where these fruits are typically seen. After removing the fruit pulp and air-drying the seeds, I measured the longest axis (hereafter "length") and the second longest axis (orthographical to the longest axis, hereafter "width") of each seeds by using a vernier caliper to the nearest $0.05 \mathrm{~mm}$. Linear discriminant analyses were then conducted using $R$ software (version 2.12.1) with these length and width measures.

I also collected 24 Saba/Landolphia-shaped seeds from a chimpanzee fecal clump found during the same study period. After washing and air-drying, their length and width were measured in the same way. The size data for these seeds were used in order to trial-run the applicability of the analysis.

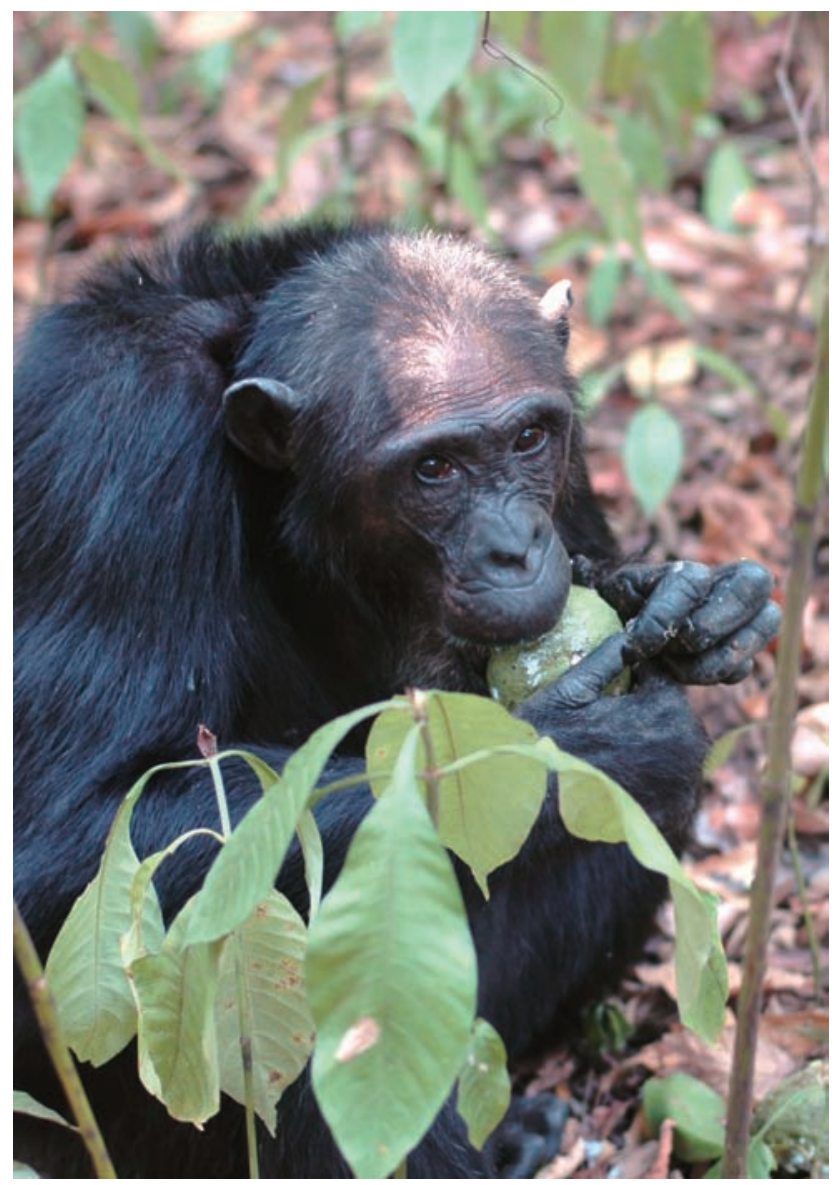

A Mahale chimpanzee feeding on a Saba fruit. 


\begin{tabular}{lc}
\hline Pan Africa News, 21(1), June 2014 & 5 \\
\hline
\end{tabular}

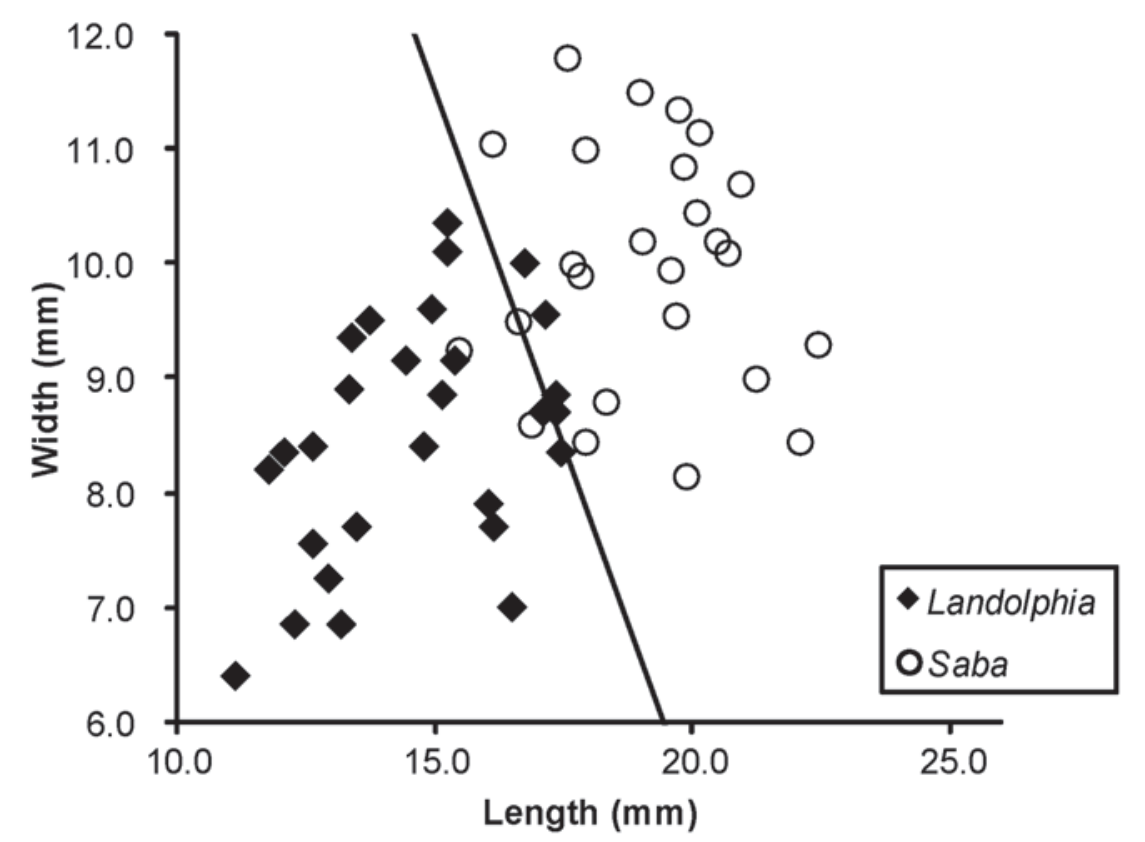

Figure 2. Length-width plots of known Saba and Landolphia seeds. The line is the discrimination line between the two species (i.e., $D_{\mathrm{sp}}=0$ ). Although a few seeds of each species are inaccurately judged as the other, $88.68 \%$ of the data points are plotted on the correct sides of the line.

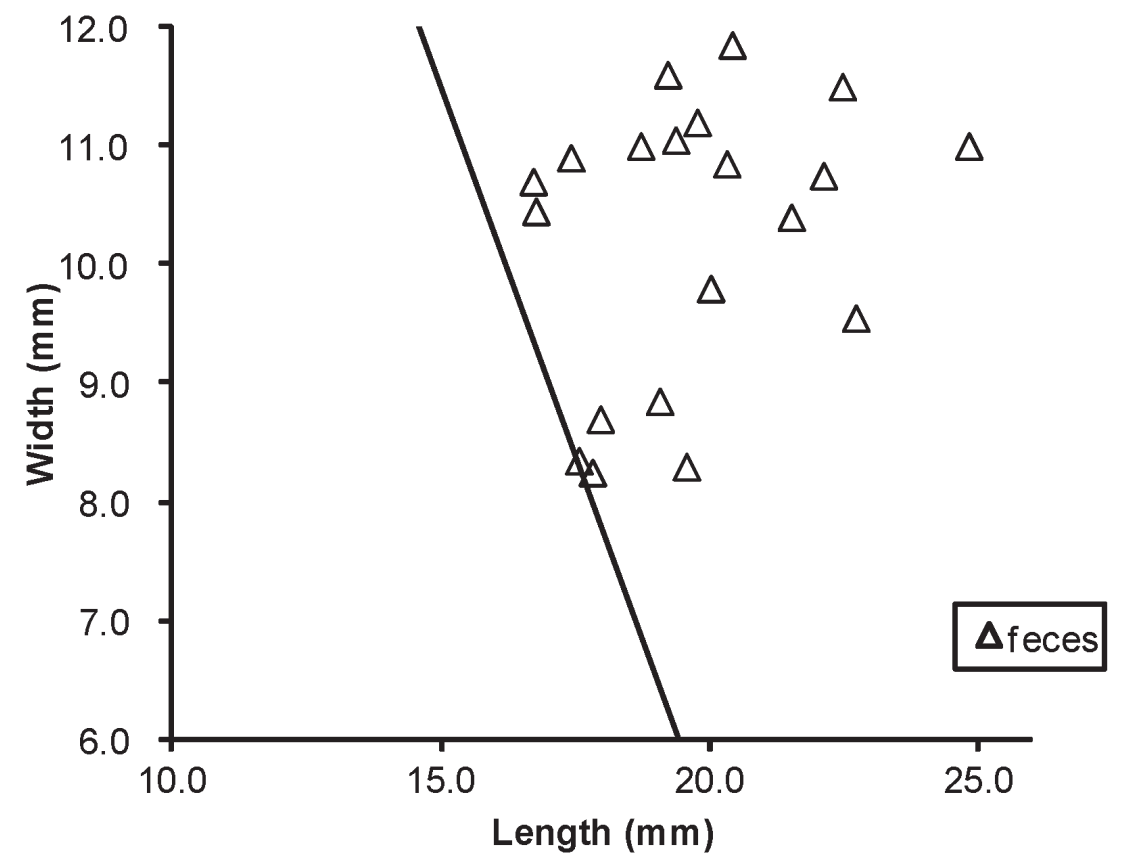

Figure 3 . Length-width plots of unknown SabalLandolphia-shaped seeds from chimpanzee feces. The line is the same discrimination line (i.e., $D_{\mathrm{sp}}=0$ ) as that in Figure 2. Almost all seeds are plotted on the side of Saba.

\section{RESULTS AND DISCUSSION}

The length and width data for known $S a b a$ and Landolphia seeds are plotted in Figure 2. Saba seeds averaged $19.06( \pm 1.81 \mathrm{SD}) \mathrm{mm}$ in length and $9.97( \pm 1.05) \mathrm{mm}$ in width, while Landolphia seeds averaged $14.64( \pm 1.92) \mathrm{mm}$ by $8.49( \pm 1.05) \mathrm{mm}$. Saba tends to have a longer and wider shape than Landolphia, but there is still some overlap in their sizes. It seems that length has less overlap than width (thus, $S a b a$ is relatively longer and ovoid than Landolphia).

Linear discriminant analysis yielded the discriminating function of the two species $\left(D_{\mathrm{sp}}\right)$ in the following formula:

$$
D_{\text {sp }}(L, W)=-0.455 \times L-0.367 \times W+11.06
$$

where $L$ is the length and $W$ is the width of a seed in millimeters. When the $D_{\mathrm{sp}}$ value is negative, the seed is judged to be that of $S a b a$, and when it is positive, judged as Landolphia. Re-evaluation of the original data set in this formula resulted in the misidentification of three Saba seeds as Landolphia and three Landolphia as Saba. Thus, discrimination accuracy was $88.68 \%$ (47/53).

When length/width values of the 24 unidentified Saba/Landolphia-shaped seeds from a chimpanzee fecal clump were assigned to this formula, all but one was judged as Saba (Figure 3). I assume that the fecal 
clump actually contained only Saba seeds (i.e., one was misjudged as Landolphia) for the following reasons. First, the one judged as Landolphia was almost on the border of these two species $\left(D_{\mathrm{sp}}=0.002\right)$, and the proportion of seeds judged as $\operatorname{Saba}(95.83 \%=23 / 24)$ was higher than the discrimination accuracy of $88.68 \%$ (thus, it is very likely that a small portion was misjudged). Second, because chimpanzees usually swallow multiple seeds of a Saba/Landolphia fruit at a time, that is, a fecal clump is expected to contain multiple seeds from one fruit, it is not very likely (though not completely impossible) that only one Landolphia seed was contained in a fecal clump with many Saba seeds. In addition, direct observations of feeding at the time showed that the chimpanzees more often fed on Saba than Landolphia.

Although this result is preliminary and we may need more data by performing additional random sampling of fruits, simple measurements of the length and width of a seed seem to distinguish these two species with an accuracy of close to $90 \%$. There are, of course, more accurate ways to discriminate the species, for example, by germination tests to confirm the species by the characteristics of their seedlings or by DNA analyses to genetically identify species. However, measuring sizes is far easier for field researchers. Thus, this may be useful for future studies of chimpanzee seed dispersal and/or fecal analyses at and around Mahale, especially on unhabituated chimpanzee groups whose direct observation is often difficult but who may share similar food items with the $M$ group. A similar method may also be applicable to other study sites where Saba-Landolphia (and other confusing sets of species or genera) coexist, with modifications of the formula with their own data sets.

\section{ACKNOWLEDGEMENTS}

I would like to thank COSTECH, TAWIRI, and TANAPA for their permission to conduct long-term research at Mahale. I would also like to thank Dr. William C. McGrew for useful suggestions on the manuscript. This study was financially supported by the Toyota Foundation.

\section{REFERENCES}

McGrew WC, Baldwin PJ, Tutin CEG 1988. Diet of wild chimpanzees (Pan troglodytes verus) at Mt. Assirik, Senegal: I. Composition. Am J Primatol 16:213-226.

McGrew WC, Marchant LF, Phillips CA 2009. Standardised protocol for primate faecal analysis. Primates 590:363-366.

Nishida T 1991. Primate gastronomy: cultural food preferences in nonhuman primate and origins of cuisine. In: Chemical Senses. Vol. 4. Appetite and Nutrition, Friedman MI, Tordoff MG, Kare MR (eds), Marcel Dekker, Inc, New York, pp. 195-209.

Nishida T, Norikoshi K n.d.1. The study of food on a basis of fecal analysis of the chimpanzees of the K-group and the M-group, June-November, 1975. Mahale Mountains Chimpanzee Research Project Ecological Report 1 (unpublished report).

Nishida T, Norikoshi K n.d.2. The study of food on fecal analysis of the chimpanzees of the K-group and the M-group, December 1975-May 1976. Mahale Mountains Chimpanzee Research Project Ecological Report 2 (unpublished report).

Takasaki H 1983. Seed dispersal by chimpanzees: a preliminary note. Afr Stud Monogr 3:105-108.
Takasaki H, Uehara S 1984. Seed dispersal by chimpanzees: supplementary note 1. Afr Stud Monogr 5:91-92.

\section{$<$ NOTE > \\ Homosexual Interactions among Young Female Wild Chimpanzees: An Example of Social Pretend Play?}

\author{
Masaki Shimada \\ Teikyo University of Science, Japan \\ (E-mail: masakishimada@japan.email.ne.jp)
}

\section{INTRODUCTION}

Homosexual behavior among animals is ethologically defined as a display of courtship that involves mounting and/or genital contact and stimulation between samesex individuals (Vasey \& Sommer 2006, p10). Several studies have examined homosexual behaviors between two females of the genus Pan. Wild female bonobos ( $P$. paniscus) frequently engage in homosexual interactions such as genito-genital rubbing (GG-rubbing; e.g., Fruth \& Hohmann 2006). Conversely, wild female chimpanzees ( $P$. troglodytes) rarely engage in homosexual interactions (Zamma \& Fujita 2004), even though young captive female chimpanzees in a group engaged in GG-rubbing as frequently as did wild bonobos (Anestis 2004). During homosexual interactions, it has been observed that most wild female bonobos rub their genital regions on a lateral axis in the ventroventral position, and rarely engage in pelvic thrusts (Fruth \& Hohmann 2006). Captive female chimpanzees, in contrast, rub their genital regions on a front-back axis in the dorsoventral position (Anestis 2004). Homosexual interactions between female bonobos frequently occur during feeding, when group excitement is high (Fruth \& Hohmann 2006). In captive chimpanzees, however, most interactions occur during group rest periods (Anestis 2004). Only one previously observed case of homosexual interaction between chimpanzee females of the Mahale $\mathrm{M}$ group occurred during a relaxed situation (Zamma \& Fujita 2004).

Several hypotheses have been proposed and tested regarding the function of homosexual behavior between Pan females (Anestis 2004; Fruth \& Hohmann 2006). However, in other animal species, such as American bison (Bison bison) (Vervaecke \& Roden 2006) or cervid species (Bartoš \& Holečková 2006), some homosexual interactions between young females were interpreted as social play or biologically functionless byproducts of adaptations (Vasey \& Sommer 2006). Although Anestis (2004, p481) reported that one captive female chimpanzee vocalized play-panting with play-face during a homosexual interaction, researchers have not discussed the possibility that homosexual interactions between wild Pan females are a pattern of social play. In this article, I describe an observed case of homosexual interaction between wild female chimpanzees, and discuss the property 